\title{
Globe
}

Revue internationale d'études québécoises

Michel Sarra-Bournet et al. : Le Pays de tous les Québécois, Diversité culturelle et souveraineté, Montréal, VLB éditeur, 1998, 249 p.

\section{Angelo Soares}

Volume 1, numéro 1, 1998

URI : https://id.erudit.org/iderudit/1000130ar

DOI : https://doi.org/10.7202/1000130ar

Aller au sommaire du numéro

Éditeur(s)

Globe, Revue internationale d'études québécoises

ISSN

1481-5869 (imprimé)

1923-8231 (numérique)

Découvrir la revue

Citer ce compte rendu

Soares, A. (1998). Compte rendu de [Michel Sarra-Bournet et al. : Le Pays de tous les Québécois, Diversité culturelle et souveraineté, Montréal, VLB éditeur, 1998, 249 p.] Globe, 1(1), 121-124. https://doi.org/10.7202/1000130ar d'utilisation que vous pouvez consulter en ligne.

https://apropos.erudit.org/fr/usagers/politique-dutilisation/ 
surtout, d'immenses possibilités d'interaction. Mais encore faut-il avoir un ordinateur et un accès à Internet... Pour le moment, le site reste une ressource fort utile pour les internautes, mais complémentaire aux ouvrages imprimés.

Si l'accès à la banque de données est gratuit, on songe à imposer des frais pour les critiques d'œuvres. Les utilisateurs auront le choix entre l'abonnement et la consultation ponctuelle, payable en fonction de la quantité de documentation obtenue. L'initiative est audacieuse : les sites Intemet québécois avec accès restreint ou les services payants sont relativement rares et lidée est en général peu appréciée des intemautes. Mais la facilité d'accès et la rapidité de téléchargement des documents sauront peut-être convaincre les usagers récalcitrants. Reste à connaittre les détails de la facturation : comment, et surtout, combien? L'île n'en demeure pas moins un excellent site de référence dans le domaine de la littérature québécoise, et peut s'avérer être extrêmement utile pour les chercheurs.

Isabelle Giroux

Université de Montréal

Michel Sarra-Bournet et al.

Le Pays de tous les Québécois

Diversité culturelle et souveraineté

Montréal, VLB éditeur, 1998, 249 p.

Dans Le Pays de tous les Québécois. Diversité culturelle et souveraineté, plusieurs auteur-e-s, souverainistes ou non, ont été invité-e-s par le regroupement des Intellectuels pour la souveraineté (IPSO) à réfléchir sur les relations interculturelles dans un Québec souverain. L'ensemble des textes nous brosse un portrait des différents points de vue qui constituent le débat sur le nationalisme, la culture et les rapports sociaux de races et d'ethnies au Québec. Il s'agit d'une œuvre intéressante, 
multidisciplinaire et accessible à un grand public, mais inégale en ce qui conceme son contenu.

Le livre s'organise en trois parties bien équilibrées. Dans la première partie, «Solidarités», cinq textes jettent différents regards sur l'interculturalisme québécoise et donnent plusieurs témoignages des néoquébécois sur le mouvement souverainiste.

Dans la deuxième partie, "Langue et culture», six textes proposent des réflexions intéressantes sur les rapports entre la langue et la culture. Dans cette partie, il faut remarquer le texte de Pierre Noreau, qui soulève plusieurs aspects importants concemant le débat linguistique au Québec. Par exemple, la manière restrictive et statique dont la culture commune au Québec est traitée lorsqu'on reste limité au problème de la langue (p. 133). L'auteur souligne qu'une des difficultés du mouvement souverainiste, difficulté très importante, est de transposer les dimensions culturelles (pas seulement la question linguistique !) sur le plan politique. Dans ce même courant, le texte de $M$. Kai Nielsen aborde la dimension culturelle du concept de nation.

Finalement, dans la troisième partie, six textes enrichissent le débat autour du concept de "citoyenneté». En particulier, le texte de Bjarne Melkevik permet de réfléchir sur le cas québécois, à partir de la lutte des Norvégiens pour leur indépendance. Finalement, le texte de Michel Sama-Boumet offre une réflexion sur l'importance de la citoyenneté québécoise dans la construction de l'identité québécoise.

Ce livre fait une mise au point sur les différents aspects qui constituent le débat autour du mouvement souverainiste québécois. Cependant, trois dimensions importantes ont été oubliées.

D'abord, l'importance des mouvements sociaux, non seulement à l'intérieur même du mouvement souverainiste québécois, mais surtout dans la construction des relations interculturelles, ainsi que dans la construction de la culture québécoise. Par mouvement social, nous entendons «l'action collective des groupes sociaux ou de forces sociales diversifiés, en 
vue de la défense d'une cause et phus particulièrement, de mouvements qui ouvrent une crise politique dont l'issue peut être variable»'1. Ainsi, le débat s'appauvrit lorsque le livre ne prend pas en considération le rôle des différents mouvements sociaux dans le mouvement souverainiste : par exemple, comment le mouvement syndical québécois a-t-il contribué et continue-t-il de contribuer à la construction de la culture, de l'identité québécoise et du mouvement souverainiste ? Quel est le rôle des mouvements sociaux, entamés par les différents regroupements ethniques, dans la construction du mouvement souverainiste québécois?

Ensuite, il me semble important de situer le mouvement souverainiste à l'époque actuelle où le système capitaliste traverse un profond changement, l'avènement du néolibéralisme. Ainsi, on assiste à un abandon des politiques sociales (privatisations), à une précarisation sociale, à un taux élevé du chômage et à un abandon de la planification économique faite par l'État (déréglementation). Comment, par exemple, peut-on dissocier les effets sociaux néfastes des politiques néolibérales des conséquences d'un Québec indépendant ? Dans ce même sens, la question posée par Michel Sarra-Bournet dans l'introduction du livre, à savoir si le symbolisme de l'État-nation qui joue en faveur du Canada pourra susciter un fort sentiment d'appartenance au Québec, serait mieux comprise si cette mise en situation avait été être faite.

Finalement, la dimension manquante la plus importante consiste en l'absence d'une analyse du mouvement pour la souveraineté du Québec en tant que mouvement social sexué, c'est-à-dire cal ne s'agit pas de "rajouter" les femmes comme un plus qui viendrait colorer le mouvement social (...). Mais cela signifie que les rapports sociaux de sexe imprègnent en permanence en profondeur tous les mouvements que cette

1 J. Trat, «Hommes et femmes dans le mouvement social», Cahiers $d u$ GEDISST, 1997, 18, pp. 5-17. 
considération doit toujours être présente quand on les analyse $\aleph^{2}$. $\grave{A}$ travers les textes qui forment ce livre, les rapports sociaux de sexe sont absents, ce qui est à déplorer, surtout lorsqu'on sait que les femmes ont joué et continuent de jouer un rôle important au sein du mouvement souverainiste. Malheureusement, les femmes sont une autre fois absentes de l'histoire.

Angelo Soares

Université du Québec à Montréal

\section{David Morrison et Louis Caron}

Terre des Inuit.

Un séjour inoubliable sur le toit du monde.

Cédérom hybride Macintosh et PC produit par Édirom et le Musée canadien des civilisations.

Coproduit par le Musée canadien des civilisations et la compagnie Édirom, le cédérom Terre des Inuit constitue à la fois une fascinante introduction au monde nordique et à la culture inuit, et un document permettant des recherches plus détaillées. La qualité de cette nouvelle parution tient à sa versatilité: son aspect ludique, à travers la reconstitution du récit historique de l'explorateur anglais Francis Crozier et ses défis révélant différents aspects de la culture, permet de découvrir ce monde sans être perdu dans des masses de renseignements. Par ailleurs, à toutes les étapes du récit historique ou des défis, des liens discrets, mais utiles, vers les fiches encyclopédiques donnent des précisions sur la culture, l'histoire, la langue, le climat et les activités inuit. En introduction, on trouve aussi

2 D. Kergoat et coll., Les Infirmières et leur coordination 1988-1989, Paris, Édition Lamarre, 1992, p. 122. 